\title{
A 2-Year Psychological Autopsy Study of Completed Suicides in the Athens Greater Area, Greece
}

\author{
Antonios Paraschakis ${ }^{1}$, loannis Michopoulos ${ }^{2}$, Christos Christodoulou ${ }^{2}$, \\ Filippos Koutsaftis ${ }^{3}$, Lefteris Lykouras ${ }^{2}$, and Athanassios Douzenis ${ }^{2}$ \\ 'Psychiatric Hospital of Attica "Dafni", Athens, Greece \\ ${ }^{2} 2$ nd Department of Psychiatry, Athens University Medical School, "Attikon" General Hospital, Athens, Greece \\ ${ }^{3}$ Athens Department of Forensic Medicine, Athens, Greece
}

\begin{abstract}
Objective To study the characteristics of a sample of suicide victims from the Athens Greater Area using the psychological autopsy method for the first time in Greece.

Methods We studied all recorded cases of completed suicide for the 2-year time period November 2007-October 2009 collecting data from the victims' forensic records as well as from the completion of a psychological autopsy questionnaire.

Results 335 persons were recorded as suicide victims. We contacted relatives of 256 victims interviewing those of 248 of them (96.9\%). The differences regarding sex, marital and employment status between our sample and the general population were statistically significant $(\mathrm{p}<0.001)$. The male/female ratio was 3:1. Comparatively more victims were divorced, separated or single and a greater proportion were pensioners or unemployed. $26.0 \%$ of the victims had history of prior attempts $(64.4 \%$ once, $20.3 \%$ twice and $15.3 \%$ more times). $42.6 \%$ were taking psychiatric medication-significantly more women than men according to blood tests; $14.2 \%$ had been hospitalized in a psychiatric clinic the year prior to their death. $84.8 \%$ have deceased at the place of suicide and $15.2 \%$ died in the hospital; $80.3 \%$ died indoors and $19.7 \%$ outdoors. Men died primarily by hanging or shooting by a firearm while women preferred jumping from height instead $(\mathrm{p}<0.001)$. As many as $48.8 \%$ had expressed their intention to die to their relatives; $26.6 \%$ left a suicide note.

Conclusion Our study has shown that the psychological autopsy method is applicable and widely accepted yielding results comparable to the international literature. Specific parameters associated with suicide have been studied for the first time in Greece.
\end{abstract}

Psychiatry Investig 2015;12(2):212-217

Key Words Psychological autopsy, Completed suicides, Athens greater area, Greece.

\section{INTRODUCTION}

Suicide is a complex phenomenon involving numerous parameters: Socio-demographic, genetic, environmental, medical, and psychiatric..$^{1-3}$ Each one of them contributes-to a different extent-in increasing the suicide risk of a particular individual at a given time period. Last but not least, social circumstances and situational factors can play a key role in adding a critical stressor to an already vulnerable individual. ${ }^{4,5}$

Received: February 28, 2014 Revised: June 16, 2014

Accepted: June 16, 2014 Available online: January 20, 2015

$\triangle$ Correspondence: Antonios Paraschakis, MD

Psychiatric Hospital of Attica “Dafni”, 95, Ioanninon Str, P.O.BOX 16674, Glyfada, Athens, Greece

Tel: +30 210 9636097, Fax: +30 213 2054300, E-mail: antparaschakis@yahoo.gr

(c) This is an Open Access article distributed under the terms of the Creative Commons Attribution Non-Commercial License (http://creativecommons.org/licenses/by$\mathrm{nc} / 3.0$ ) which permits unrestricted non-commercial use, distribution, and reproduction in any medium, provided the original work is properly cited.
Every year approximately 1,000,000 people die by suicide: It is estimated that by the year 2020 this number will rise to $1,500,000 .{ }^{6}$ Greece has one of the lowest suicide rates worldwide according to the latest available data from the WHO (referring to the year 2009): The mean standardized suicide rate in our country was 3.5/100,000:6/100,000 for men and $1 / 100,000$ for women. ${ }^{6}$ Unfortunately, according to national official data, a rise of $16.1 \%$ has been already observed in the number of suicides between 2007 and 2009, and all this even before the escalation of the recent severe economic crisis that has afflicted Greece during the last 4 years. ${ }^{7}$ In fact, even though official data are not provided for the years 2010 to 2012 , unofficially a $40 \%$ increase is reported in the number of suicides between 2009 and 2010; consequently, the suicide rate is expected to rise considerably. ${ }^{8}$

A number of previous studies have been focused on the phenomenon of suicide in Greece. ${ }^{9-13}$ However, none of them 
has used the method of psychological autopsy. The psychological autopsy, developed by Shneidman, is a well-tested method of investigating completed suicides. ${ }^{14}$ It joins interviews with relatives of the deceased together with material from the victims' forensic records aiming to create an, as accurate as possible, profile of the victim. It provides extra information to the coroner sometimes facilitating him in defining the cause of death. It is currently considered the most direct method available for studying the relation between particular risk factors and completed suicide. ${ }^{15,16}$

\section{METHODS}

For the purpose of our study we developed a psychological autopsy questionnaire based on the most established scientific knowledge about suicide risk factors. ${ }^{17-19}$ We included sociodemographic parameters, psychiatric medication intake, and history of previous attempts and of recent -within the previous 12 months- psychiatric hospitalization. We were also focused on the characteristics of the suicidal act itself.

Material for our study was provided by the Athens Department of Forensic Medicine (ADFM), the largest, by far, of its kind in Greece. The ADFM covers the Athens area and its suburbs as well as a number of contiguous counties where approximately $35 \%$ of Greece's $10,964,020$ population lives. ${ }^{7}$ We studied all recorded cases of completed suicides for the 2-year period November 2007-October 2009. All interviews with relatives were conducted by phone usually 2-4 months after the victim's death; this time interval is generally accepted as appropriate in the literature..$^{20,21}$

We have compared the socio-demographic characteristics of our sample with the characteristics of the general population of the Athens Greater Area. The data, provided by the Hellenic Statistics Authority, referred to the last population census prior to the study (2001 census). We compared males and females regarding marital status and types of psychiatric medications found at the blood tests. We performed the same comparison for the suicide methods employed by the two sexes.

Statistical analysis was carried out by the Pearson's $\chi^{2}$ test for comparison of percentages and the t-test for comparison of means of variables. The level of $\mathrm{p}<0.05$ was chosen to indicate statistical significance.

The study was granted approval by the Ethics committee of the "Attikon" General Hospital, and from the head of the ADFM who provided unconditional access to the victims' forensic records.

\section{RESULTS}

During the 2-year period of our study 335 individuals were recorded as suicide victims: 250 men (74.7\%) and 85 women (25.3\%). Mean age of our sample was 53.3 years and standard deviation was 18.3 years. The youngest victim was an 18 -year old; the oldest was a 97-year old.

We contacted the relatives of 256 victims (76.4\%); for the rest, a phone number was unavailable. We interviewed those of 248 of them (response rate: $96.9 \%$ ). In 8 cases the relatives were unwilling to cooperate.

The differences regarding sex, marital and employment status between our sample and the general population were statistically significant $(\mathrm{p}<0.001)$. More men than women died by suicide. Comparatively more of the victims were divorced, separated or single; finally, more were pensioners or unemployed. The socio-demographic characteristics of our sample compared to those of the general population of the Athens Greater Area are shown in Table 1.

The difference regarding the marital status in relation to the victims' sex was statistically significant too $(\mathrm{p}<0.001)$ : A great-

Table 1. Socio-demographic characteristics of the sample and of the general population in the Athens Greater Area $(3,837,402$ inhabitants)

\begin{tabular}{|c|c|c|c|}
\hline & $\begin{array}{c}\text { Sample } \\
(\%)\end{array}$ & $\begin{array}{l}\text { Population } \\
(\%)\end{array}$ & $\mathrm{p}^{*}$ \\
\hline $\operatorname{Sex}(N=335)$ & & & $<0.001$ \\
\hline Male & 74.3 & 45.7 & \\
\hline Female & 25.7 & 54.3 & \\
\hline $\begin{array}{l}\text { Age specific suicide frequencies } \\
(\mathrm{N}=335 \text {, age in years })\end{array}$ & & & $<0.001$ \\
\hline$<18$ & 0 & 20.7 & \\
\hline $18-24$ & 4.8 & 8.0 & \\
\hline $24-34$ & 15.2 & 17.0 & \\
\hline $35-44$ & 17.3 & 15.1 & \\
\hline $45-54$ & 22.7 & 13.6 & \\
\hline $55-64$ & 12.6 & 10.5 & \\
\hline $65-74$ & 10.7 & 9.5 & \\
\hline$>75$ & 16.7 & 5.6 & \\
\hline Family status $(\mathrm{N}=248)$ & & & $<0.001$ \\
\hline Single & 36.9 & 31.0 & \\
\hline Married & 36.5 & 57.3 & \\
\hline Divorced-separated & 17.7 & 3.4 & \\
\hline Widowed & 9.0 & 8.3 & \\
\hline Employment status $(\mathrm{N}=248)$ & & & $<0.001$ \\
\hline Private sector employees & 42.9 & 39.2 & \\
\hline Pensioners & 32.3 & 16.7 & \\
\hline Unemployed $^{\dagger}$ & 9.4 & 4.4 & \\
\hline Civil servants & 8.6 & 11.9 & \\
\hline Students & 2.3 & 8.8 & \\
\hline Housewives & 2.3 & 16.8 & \\
\hline Others & 2.3 & 2.2 & \\
\hline
\end{tabular}

${ }^{*} \mathrm{p}<0.05,{ }^{\dagger}$ during-at least-the previous 6 months 
er proportion of men were single, divorced or separated while more women were widowed. Women were more frequently under psychiatric medication than men for all kinds of the drugs examined. Finally, there was a different choice of methods among the sexes $(\mathrm{p}<0.001)$ : More men chose hanging or shooting by a firearm while women preferred jumping from a height. In Table 2 are pictured the abovementioned differences.

As many as $24.0 \%$ of suicide completers had attempted suicide in the past: $64.4 \%$ once, $20.3 \%$ twice, $15.3 \%$ more times; $14.2 \%$ had been hospitalized in a psychiatric clinic during the year prior to their death. The overwhelming majority $(84.8 \%)$ of the victims died at the place of suicide and only a minority in the hospital (15.2\%). Indoor incidence was four times that of the outdoor incidence $(80.3 \%$ vs. $19.7 \%)$.

Approximately half (48.8\%) of the victims had verbally communicated their intention to die to their relatives and $26.6 \%$ left suicide notes. Various settlements, such as writing a will or paying-off debts were made by $10.2 \%$ of the victims during the weeks or months prior to the suicide.

Employment status, history of prior attempts, psychiatric medication intake, recent psychiatric hospitalization, indoor and outdoor incidence as well as communication of suicide in-

Table 2. Family status, psychiatric medication intake and suicide methods according to the victims' sex

\begin{tabular}{|c|c|c|c|c|}
\hline & \multicolumn{2}{|c|}{ Sample (\%) } & \multirow{2}{*}{$\begin{array}{c}\text { Total } \\
(\%)\end{array}$} & \multirow{2}{*}{$\mathrm{p}^{*}$} \\
\hline & Males & Females & & \\
\hline Family status $(\mathrm{N}=248)$ & & & & $<0.001$ \\
\hline Single & 39.9 & 26.9 & 36.9 & \\
\hline Married & 36.7 & 37.3 & 36.5 & \\
\hline Divorced-separated & 18.6 & 14.9 & 17.7 & \\
\hline Widowed & 4.8 & 20.9 & 9.0 & \\
\hline \multicolumn{5}{|l|}{ Medications $(\mathrm{N}=248)$} \\
\hline Antidepressants & 11.3 & 32.8 & 16.8 & $<0.001$ \\
\hline Antipsychotics & 9.2 & 24.2 & 13.0 & 0.003 \\
\hline Benzodiazepines & 6.6 & 16.7 & 9.2 & 0.024 \\
\hline Anticonvulsants & 0.5 & 9.1 & 2.7 & 0.001 \\
\hline Suicide methods $(\mathrm{N}=335)$ & & & & $<0.001$ \\
\hline Jumping from a height & 23.9 & 64.3 & 34.0 & \\
\hline Hanging & 38.6 & 17.9 & 33.4 & \\
\hline Shooting by a firearm & 21.9 & 1.2 & 16.7 & \\
\hline Self immolation & 2.8 & 5.9 & 3.6 & \\
\hline $\begin{array}{l}\text { Poisoning by solid } \\
\text { or liquid substances }\end{array}$ & 3.2 & 2.4 & 3.6 & \\
\hline Cutting & 3.2 & 1.2 & 2.7 & \\
\hline Run over by train & 3.2 & 1.2 & 2.7 & \\
\hline Drowning & 2.0 & 2.4 & 2.1 & \\
\hline Medication overdose & 1.2 & 3.6 & 1.8 & \\
\hline
\end{tabular}

tent were parameters investigated for the first time in a study on suicides in Greece.

\section{DISCUSSION}

Most of the findings of our study are supported by the relevant literature as we shall see in detail in the oncoming parts.

\section{Socio-demographic characteristics}

The male/female ratio (3:1) of suicide victims is in complete accordance with that of the last extensive study on suicides in Greece conducted by Zacharakis et al. ${ }^{10}$ The fact that men die more often by suicide than women is constantly found in the literature at least in Western industrialized nations. ${ }^{22,23}$ In comparison to women, men seem to be more reluctant to address themselves to psychiatric services when faced with psychological difficulties, they are less frequently recognized as suffering from depressive disorders by health care professionals and they choose more violent-therefore lethal-suicide methods. $^{24}$

Suicide frequency was very low in the young subjects and very high among the elderly ones. This finding agrees with similar studies confirming an increase of suicide risk with age. ${ }^{25}$ Worldwide, suicide risk is low in adolescents and high in the "very old" age group (>75 years) ${ }^{26}$ Similar findings have been reported for Greece too. ${ }^{27}$

Relatively more of the victims were divorced or separated in comparison to the general population; less was married. Our results are in concordance with those of similar studies where the protective effect of marriage and the stress of separation has been adequately emphasized. ${ }^{28-30}$ Comparatively more men were single, divorced or separated and more women widowed. It could be suggested that the single status increases the suicide risk for men, while marriage seems to have a protective effect for them. ${ }^{31-34}$ Furthermore, divorce or separation is apparently an important stress primarily for men while widowhood seems to be a respective stress for women.

More of the victims were pensioners or unemployed in comparison to the general population. It is well known that pensioners are at high risk of suicide for various reasons: Advanced age, retirement, health problems, loss of relatives or friends and loneliness. ${ }^{35-37}$ Unemployment could also significantly increase suicide risk: Economic problems, loss of working status, isolation and low self-esteem could exert a pro-suicide influence. ${ }^{38-40}$

\section{History of prior attempts and of psychiatric hospitalization}

Approximately one quarter of the victims (24.0\%) had history of prior attempt(s); more than half of them once. This 
proportion is lower to the one reported by some studies where approximately one third of suicide completers had history of prior attempts. ${ }^{21,41}$ However, other researchers report even higher percentages arriving, or surpassing, $40 \% .{ }^{42,43}$ Our finding also implies that over three quarters of suicide completers had never been attempters in the past. This result stresses the difficulties of the suicide prevention task, given the fact that history of prior attempt(s) represents the single strongest predicting factor for future completed suicide. ${ }^{44,45}$

As many as $14.2 \%$ of the suicide victims had been hospitalized in a psychiatric clinic the year prior to their death. It is well-known that history of a recent psychiatric hospitalization is associated with a very high risk of suicide: Former psychiatric inpatients have an estimated 16-fold risk of suicide compared to the risk for patients treated in primary care. ${ }^{31,46}$ The risk seems to be particularly high the first 3 months after discharge peaking during the first week. ${ }^{47,48}$

\section{Psychiatric medication intake}

Nearly 4 out of 10 victims were taking psychiatric medication (antidepressants, antipsychotics, benzodiazepines or anticonvulsants) at the time of their death. It has been reported that between $33 \%$ and $70 \%$ of suicide completers are receiving some kind of psychiatric medication when they die. ${ }^{49,50}$ The proportion of women taking psychiatric medications was considerably higher that of men in our sample regardless of the drugs investigated; the difference was more pronounced for antidepressants and less so for benzodiazepines. Our findings are confirmed by similar studies. ${ }^{51,52}$

\section{Characteristics of the suicidal act}

The most frequent suicide methods were jumping from a height, hanging and self-shooting by a firearm. These methods-all particularly violent-represent an indication of a strong determination to die; ${ }^{12,53}$ the last is confirmed by the fact that the vast majority of the victims were found dead at the place of suicide. Both jumping from a height and hanging are easily accessible methods while hanging, in particular, is less likely to be misclassified as accidental or undetermined death. ${ }^{10}$ Men chose more violent methods when they decided to die in comparison with women with the exception of self-immolation; finally, firearms were used almost exclusively by men. Our findings are supported by similar studies. ${ }^{23,53,54}$

Approximately one quarter of the victims left suicide notes. Worldwide, the incidence of note leaving varies considerably ranging from 3 to $42 \% .{ }^{55-59}$ It should be mentioned though that, while the presence of a suicide note is generally considered as an indication of a serious attempt, its absence doesn't necessarily point to a less serious intention. ${ }^{60}$

Nearly half of the victims (48.8\%) had expressed their in- tention to die to their relatives. In this parameter the actual number would most likely be higher given the fact that we interviewed only one relative for every case; suicidal intention could have been communicated to another relative instead. Even though this parameter has not been extensively investigated in a similar way, it has been referred that a considerable part of suicide completers-arriving to $69 \%$-had previously expressed their desire to die to their relatives. ${ }^{61}$

\section{Conclusions}

Psychological autopsy was implemented for the first time in our country. We searched an extensive number of parameters. Many of them, such as the victim's employment status, history of prior attempts, psychiatric medication intake prior to the suicidal act, history of hospitalization in a psychiatric clinic the year prior to the death, indoor and outdoor suicide incidence as well as investigation of suicidal communication were studied for the first time in Greece. Most of our findings are in accordance with those of similar studies in the literature.

More than $95 \%$ of the relatives contacted agreed to participate in the phone survey; this constitutes a fairly encouraging result. It also provides a motive for additional research valuable for preventive strategy planning much needed given the expected rise in suicides in Greece.

\section{Limitations}

Our study presents various limitations. Above all, there is no standardized method of conducting psychological autopsy studies worldwide. ${ }^{62}$ Secondly; we weren't able to find the phone number of a relative in approximately $1 / 4$ of the suicide cases. We performed all interviews by phone and with only one relative per case due to financial reasons. This may have caused information loss-and data validity problems-, that direct interviews with more than one relative per case could have prevented. There was also the risk of information bias due to the informants' feelings of guilt or shame and of data loss due to memory decay. Furthermore, we didn't make use of a control group. Finally, our results should not be considered representative of the whole country given the fact that the study covered only the Athens Greater Area.

\section{Acknowledgments}

We are deeply grateful to the staff of the Athens Department of Forensic Medicine, in particular to Maria Terzi and Natassa Apostolopoulou for providing useful support in data collection and to Dimitris Manifavas (mortuary staff) for his valuable aid in the search for the relatives' phone numbers. Furthermore, we are immensely thankful to the relatives of the victims for their collaboration in the present study.

\section{REFERENCES}

1. Lin PI, Vance JM, Pericak-Vance MA, Martin ER. No gene is an island: the flip-flop phenomenon. Am J Hum Genet 2007;80:531-538. 
2. Voracek M, Loibl LM. Genetics of suicide: a systematic review of twin studies. Wien Klin Wochenschr 2007;119:463-475.

3. Kendler KS. Genetic and environmental pathways to suicidal behaviour: reflections of a genetic epidemiologist. Eur Psychiatry 2010;25: 300-303.

4. Nierenberg AA, Alpert JE, Gaynes BN, Warden D, Winsniewski SR, Biggs MM, et al. Family history of completed suicide and characteristics of major depressive disorder: a STAR ${ }^{\star} \mathrm{D}$ (sequenced treatment alternatives to relieve depression) study. J Affect Disorder 2008;108:129134.

5. Wasserman D, Geijer T, Sokolowski M, Rozanov V, Wasserman J. Nature and nurture in suicidal behavior, the role of genetics: some novel findings concerning personality trends and neural conduction. Physiol Behav 2007;92:245-249.

6. World Health Organization. WHO mortality database. http://www. whoint/healthinfo-/morttables/en/. Accessed February 14, 2014.

7. Hellenic Statistical Authority 2013. http://www.statistics.gr/portal/page /portal/ ESYE. Accessed February 14, 2014.

8. Kentikelenis A, Karanikolos M, Papanicolas I, Basu S, McKee M, Stuckler D. Health effects of financial crisis: omens of a Greek tragedy. Lancet 2011;378:1457-1458.

9. Bazas T, Jemos J, Stefanis K, Trichopoulos D. Incidence and seasonal variation of suicide mortality in Greece. Compr Psychiatry 1979;20:1520.

10. Zacharakis CA, Madianos MG, Papadimitriou GN, Stefanis CN. Suicide in Greece 1980-1995: patterns and social factors. Soc Psychiatry Psychiatr Epidemiology 1998;33:471-476.

11. Vougiouklakis T, Boumba VA, Mitselou A, Peschos D, Gerontopoulos $\mathrm{K}$. Trends in suicide mortality in the deprived region of Epirus (northwest Greece) during the period 1998-2002. Med Sci Law 2005;45:3946.

12. Vougiouklakis T, Tsiligianni C, Boumba VA. Children, adolescents and young adults suicide data from Epirus, northwestern Greece. Forensic Sci Med Pathol 2009;5:269-273.

13. Christodoulou C, Papadopoulos IN, Douzenis A, Kanakaris N, Leukidis C, Gournellis R, et al. Seasonality of violent suicides in the Athens greater area. Suicide Life Threat Behav 2009;39:321-331.

14. Shneidman ES. The psychological autopsy. Suicide Life Threat Behav 1981;11:325-340.

15. Cooper J. Ethical issues and their practical application in a psychological autopsy study of suicide. J Clin Nurs 1999;8:467-475.

16. Cavanagh JT, Carson AJ, Sharpe M, Lawrie SM. Psychological autopsy studies of suicide: a systematic review. Psychol Med 2003;33:395-405.

17. Beck AT, Kovacs M, Weissman A. Assessment of suicidal ideation: the Scale for Suicide Ideation. J Consult Clin Psychol 1979;47:343-352.

18. Beck AT, Brown GK, Steer RA. Psychometric characteristics of the Scale for Suicidal Ideation with psychiatric outpatients. Behav Res Ther 1997;35:1039-1046.

19. Kan CK, Ho TP, Dong JY, Dunn EL. Risk factors for suicide in the immediate post-discharge period. Soc Psychiatry Psychiatr Epidemiol 2007;42:208-214.

20. Beskow J, Runeson B, Asgard U. Psychological autopsies: methods and ethics. Suicide Life Threat Behav 1990;20:307-323.

21. Isometsa ET. Psychological autopsy studies-a review. Eur Psychiatry 2001;16:379-385.

22. Stark C, Hopkins P, Gibbs D, Rapson T, Belbin A, Hay A. Trends in suicide in Scotland 1981-1999: age, method and geography. BMC Public Health 2004;4:49.

23. Hawton K, Van Heeringen K. Suicide. Lancet 2009;373:1372-1381.

24. Rutz W, Rihmer Z. Suicide in Men. In: Wasserman D, Wasserman C, Editors. Oxford Textbook of Suicidology and Suicide Prevention. Oxford: Oxford University Press, 2009, p. 249-255.

25. Rapagnani G. Suicide in the elderly. Rev Med Liege 2002;57:91-96.

26. World Health Organization. Figures and Facts about Suicide. Updated country charts. http://www.who.int/mental health/prevention/suicide/ country reports/en/. Accessed February 15, 2014.

27. Paraschakis A, Douzenis A, Michopoulos I, Christodoulou C, Vassilopoulou K, Koutsaftis F, et al. Late onset suicide: distinction between "young-old" vs. "old-old" suicide victims. How different populations are they? Arch Gerontol Geriatr 2012;54:136-139.

28. Yip PS, Thorburn J. Marital status and risk of suicide: experience from England and Wales, 1982-1996. Psychol Rep 2004;94:401-407.

29. Masocco M, Pompili M, Vichi M, Vanacore N, Lester D, Tatarelli R. Suicide and marital status in Italy. Psychiatr Q 2008;79:275-285.

30. Masocco M, Pompili M, Vanacore N, Innamorati M, Lester D, Girardi $\mathrm{P}$, et al. Completed suicide and marital status according to the Italian region of origin. Psychiatr Q 2010;81:57-71.

31. Qin P, Agebro E, Mortensen PB. Suicide risk in relation to socioeconomic, demographic, psychiatric, and familial factors: a national register-based study of all suicides in Denmark, 1981-1997. Am J Psychiatry 2003;160:765-772.

32. Corcoran P, Nagar A. Suicide and marital status in Northern Ireland. Soc Psychiatry Psychiatr Epidemiol 2010;45:795-800.

33. Rendall MS, Weden MM, Favreault MM, Waldron $H$. The protective effect of marriage for survival: a review and update. Demography 2011; 48:481-506.

34. Pitman A, Krysinska K, Osborn D, King M. Suicide in young men. Lancet 2012;379:2383-2392.

35. Harwood DM, Hawton K, Hope T, Harriss L, Jacoby R. Life problems and physical illness as risk factors for suicide in older people: a descriptive and case control study. Psychol Med 2006;36:1265-1274.

36. Conwell Y, Thompson C. Suicidal behaviour in elders. Psychiatr Clin North Am 2008;33:333-356.

37. Li X, Xiao Z, Xiao S. Suicide among the elderly in mainland China. Psychogeriatrics 2009;9:62-66.

38. Makinen HI, Wasserman D. Labor Market, Work Environment and Suicide. In: Wasserman D, Wasserman C, Editors. Oxford: Oxford Textbook of Suicidology and Suicide Prevention, 2009, p.281-304.

39. Uutela A. Economic crisis and mental health. Curr Opin Psychiatry 2010;23:127-130.

40. Li Z, Page A, Martin G, Taylor R. Attributable risk of psychiatric and socio-economic factors for suicide from individual-level, population based studies: a systematic review. Soc Sci Med 2011;72:608-616.

41. Fushimi M, Sugawara J, Saito S. Comparison of completed and attempted suicide in Akita, Japan. Psychiatry Clin Neurosci 2006;60:289295.

42. Sinclair J, Harriss L, Baldwin DS, King EA. Suicide in depressive disorders: a retrospective case-control study of 127 suicides. J Affect Disord 2005;87:107-113.

43. DeJong TM, Overholser JC, Stockmeier CA. Apples to oranges? A direct comparison between suicide attempters and suicide completers. J Affect Disord 2010;124:90-97.

44. Tidemalm D, Langstrom N, Lichtenstein P, Runeson B. Risk of suicide after suicide attempt according to coexisting psychiatric disorder: Swedish cohort study with long term follow-up. BMJ 2008;337:a2205.

45. Yoshimasu K, Kiyohara C, Miyashita K; Stress Research Group of the Japanese Society for Hygiene. Suicidal risk factors and completed suicide: meta-analyses based on psychological autopsy studies. Environ Health Prev Med 2008;13:243-256.

46. Kisely S, Smith M, Lawrence D, Maaten S. Mortality in individuals who have had psychiatric treatment: population based study in Nova Scotia. Br J Psychiatry 2005;187:552-558.

47. Appleby L, Shaw J, Amos T, McDonnell R, Harris C, McCann K, et al. Suicide within 12 months of contact with mental health services: national clinical survey. BMJ 1999;318:1235-1239.

48. Qin P, Nordentoft M. Suicide risk in relation to psychiatric hospitalization: evidence based on longitudinal registers. Arch Gen Psychiatry 2005;62:427-432.

49. Ohberg A, Vuori E, Ojanpera I, Lonnqvist J. Alcohol and drugs in sui- 
cides. Br J Psychiatry 1996;169:75-80.

50. Isacsson G, Holmgren P, Druid H, Bergman U. Psychotropics and suicide prevention. Implications from toxicological screening of 5281 suicides in Sweden 1992-1994. Br J Psychiatry 1999;174:259-265.

51. Fanton L, Bevalot F, Schoendorff P, Lalliard S, Jdeed K, Malicier D. Toxicologic aspects of deaths due to falls from height. Am J Forensic Med Pathol 2007;28:262-266.

52. Fawcett J. Severe Anxiety and Agitation as Treatment Modifiable Risk Factors for Suicide. In: D Wasserman D, Wasserman C, Editors. Oxford: Oxford Textbook of Suicidology and Suicide Prevention, 2009, p. 407411 .

53. Nishimura A, Shioiri T, Nushida H, Ueno Y, Ushiyama I, Tanegashima A, et al. Changes in choice of method and lethality between last attempted and completed suicides: how did suicide attempters carry out their desire? Leg Med (Tokyo) 1999;1:150-158.

54. Denning DG, Conwell Y, King D, Cox C. Method choice, intent, and gender in completed suicide. Suicide Life Threat Behav 2000;30:282288.

55. Mohanty S, Sahu G, Mohanty MK, Patnaik M. Suicide in India-a four year retrospective study. J Forensic Leg Med 2007;14:185-189.
56. Kanchan T, Menon A, Menezes RG. Methods of choice in completed suicides: gender differences and review of literature. J Forensic Sci 2009;54:938-942.

57. La Vecchia C, Lucchini F, Levi F. Worldwide trends in suicide mortality, 1955-1989. Acta Psychiatr Scand 1994;90:53-64.

58. Kuwabara H, Shioiri T, Nishimura A, Abe R, Nushida H, Ueno Y, et al. Differences in characteristics between suicide victims who left notes or not. J Affect Disord 2006;94:145-149.

59. Paraschakis A, Michopoulos I, Douzenis A, Christodoulou C, Koutsaftis F, Lykouras L. Differences between suicide victims who leave notes and those who do not: a 2-year study in Greece. Crisis 2012;33: 344-349.

60. Salib E, Cawley S, Healy R. The significance of suicide notes in the elderly. Aging Ment Health 2002;6:186-190.

61. Robins E, Gassner S, Kayes J, Wilkinson RH Jr, Murphy GE. The communication of suicidal intent: a study of 134 consecutive cases of successful (completed) suicide. Am J Psychiatry 1959;115:724-733.

62. Ritchie E, Gelles MG. Psychological autopsies: the current Department of Defense effort to standardize training and quality assurance. J Forensic Sci 2002;47:1370-1372. 